\title{
Modern Requirements to the Content Selection of Teaching Physics and Mathematics, Aimed at the Development of Design and Technical Competence of Technical University Students
}

\author{
Ilsiyar M. Zaripova ${ }^{1}$, Vladimir N. Ivanov ${ }^{2}$, Zulfiya F. Zaripova ${ }^{1}$, Rovzan S. Khataeva ${ }^{3}$, Irina G. Ershova ${ }^{2}$, \\ Nadezhda I. Merlina ${ }^{4}$, Aigul R. Ganeeva ${ }^{5}$ \& Ekaterina V. Pavlova ${ }^{2}$ \\ ${ }^{1}$ Almetyevsk State Oil Institute, Almetyevsk, Russia \\ ${ }^{2}$ Chuvash State Pedagogical University named after I.Y. Yakovlev, Cheboksary, Russia \\ ${ }^{3}$ Chechen State Pedagogical Institute, Grozny, Russia \\ ${ }^{4}$ Chuvash State University named after I. N. Ulyanov, Cheboksary, Russia \\ ${ }^{5}$ Kazan (Volga region) Federal University, Kazan, Russia
}

Correspondence: Ilsiyar M. Zaripova, Almetyevsk State Oil Institute, Lenin Street, 2, Almetyevsk, Tatarstan, 423450, Russia. E-mail: ilagni@mail.ru

Received: June 13, 2015 Accepted: June 21, 2015 Online Published: June 29, 2015

doi:10.5539/jsd.v8n6p104 URL: http://dx.doi.org/10.5539/jsd.v8n6p104

\begin{abstract}
The research's relevance of the defined in the article problem is due to the fact that when the study of physical-mathematical disciplines the consolidation of the acquired knowledge occurs and the development of skills contribute to their using in manufacture problems' solving in the professional activities of the engineer. In this regard, this article is aimed at the development of modern requirements to the content selection of teaching physics and mathematics, aimed at the development of design and technical competence of technical University students. In the study of this problem the modular competency approach is set out, which allows on the base of the required competencies of future technical specialists to identify the following basic requirements for the selection of the content of teaching physics and mathematics: the disciplines' integrity and fundamentality, systematic and consistent presentation of educational material, problematic and innovativeness of their content, their interdisciplinary, professional orientation, orientation on the formation of logical thinking of students. The article can be useful in selecting and structuring the content of teaching physics and mathematics courses in high school, as well as in the future teachers' training of these disciplines.
\end{abstract}

Keywords: requirements to the content selection, physical-mathematical disciplines, design and technical competence, technical College students

\section{Introduction}

\subsection{The Relevance of the Problem}

When developing the content of education it is necessary in the learning process to simulate professional activities from the goal setting, process activities till results. This allows give students a holistic view of professional activity, to ensure the mastery of professional activity methods, to prepare them for rapid adaptation to the specific conditions of professional activity.

As a methodological basis of all scientific knowledge, mathematics and physics in technical universities are the major theoretical disciplines. Due to the high degree of abstraction mathematics becomes the Foundation for the whole science and without it can exist none of the Sciences, operating with any quantitative data, whereby it becomes a universal language to describe the real world and therefore in the professional education without its quality mastering the quality training is inconceivable.

\subsection{Goals and Objectives of Physical and Mathematical Disciplines}

The most primary goal by its importance of studying mathematics and system of mathematics education is actually mastering the subject, the application of mathematical knowledge to explore related disciplines of 
natural Sciences and special subjects. An equally important goal in mathematics' learning is its use by the students in their future professional activity to research, engineering and technical problems at manufacture. The mathematics' study develops in students the necessary for the future engineer the flexibility and rigor of thinking, enriches them intellectually. It is an undisputed fact that at all stages of the development of science, technology and engineering, engineering solutions require constant calculation and computation, the ability to build mathematical models, skills of projects' implementation, which is an integral part of engineering activities.

Courses of mathematics and physics at technical universities, typically are given in the first and second years of study and become for students one of the most difficult for perception, mainly due to the following circumstances: a large amount of material on these subjects are have to be squeezed into the narrow confines of academic hours devoted to their study; the majority of students of technical universities do not realize the necessity of studying General subjects, including mathematics and physics; mathematics deals with objects that do not exist in nature. As a result, surface study of physical-mathematical disciplines without regard to the General professional and special disciplines poorly form knowledge and skills in students, allowing them not properly navigate in practical tasks, to apply physical and mathematical knowledge to problems' solving connected with the future profession.

\subsection{Role of Physical-Mathematical Disciplines in Future Technical Specialists' Competencies Forming}

In the process of teaching physics and mathematics it is possible to form in the future engineers both as General (the ability to analyze, to synthesize, to establish the logical connection, to identify functional dependencies between processes, etc.), so specific, adequate for basic professional activities of the engineer (engineering, administrative, manufacture and technological, experimental and research) intellectual skills (Masalimova \& Nigmatov, 2015). In the study of certain branches of mathematics and physics there is a consolidation of physical-mathematical knowledge and the skills' development to use them when solving professionally oriented tasks and educational projects' realization. Under professionally oriented physical-mathematical problem is understood such problem, the condition and the requirement of which defines a model for some situations arising in professional work of the engineer, and the study of this situation by means of mathematics and physics promotes professional development of professional identity (Zaripova et al., 2014a). Training through a system of applying tasks and project tasks leads to the formation of the design and technical competence.

\section{Literature Review}

\subsection{Analysis of Federal state Educational Standards of Higher Professional Education}

In accordance with Federal state educational standards, the main goal of mathematics teaching of engineering University students is the formation of mathematical competence - the projection of common cultural and professional competences in the subject area of mathematics. Didactic core of mathematical competence is the combination of knowledge, abilities and skills in mathematics with the ability and willingness of the graduate to apply them in professional activity (which is also traditionally called the skills of mathematical simulation in the field of professional activity).

Based on the requirements of Federal state educational standard V. A. Shershneva (2011) identifies the following requirements for the content of teaching mathematics:

- the content of mathematics teaching should include fundamental backbone of scientific knowledge for defined by the educational standards branches of mathematics which define scientific picture of the world and form the scientific and logical thinking of the student;

-the training content should reflect the main objects of the future professional activity of engineering University graduates, to take into account the engineers' action system, given by the nature of his specialty, and allow to deploy his or her case professional activity;

- the content should reflect the interdisciplinary connections of teaching mathematics, to show other applications of mathematics and its connection with the prospects of scientific and technological progress and socio-economic development of society;

- the content is to allow the use of ICTs in the process of mathematical modeling in solving professionally oriented, interdisciplinary and applied mathematical problems (Plakhova, 2009).

To determine the current requirements to the content of teaching mathematics, aimed at the development of design and technical competence of technical College students in the first place is necessary to analyze the undergraduate curriculum of the Federal state educational standards of higher professional education for "the Oil and gas business" direction. 
Mathematical and natural-science cycle includes subjects: mathematics, physics, chemistry, computer science, ecology. The FSES of HPE of the third generation determine the projected results of the basic mathematical cycle study in the training direction 131000 "Oil and gas business" which means:

- to know: principles of linear algebra with elements of analytical geometry, mathematical analysis, foundations of discrete mathematics, theory of ordinary differential equations, probability theory and mathematical statistics,

- to be able to: apply mathematical methods for typical professional tasks' solving, navigate the mathematical literature, to acquire new mathematical knowledge using modern educational and information technologies, to use mathematical logic for judgments' making on relevant professional issues, to solve common tasks according to the main sections of the course, using the methods of higher mathematics,

- to possess: the methods of simplest mathematical models' constructing of typical professional tasks, methods of analysis of the substantive interpretation of the results.

\subsection{Requirements for Cultural Competency}

A study of the basic disciplines of mathematical and natural Sciences, should result to the following cultural competence forming: to be ready to categorical vision of the world, to be able to differentiate the different forms of its development; logically correctly, reasonably and clearly to build oral and written speech; be willing to cooperate with colleagues, work in a team; strive for self-development, improve their qualifications and skills; be able to evaluate critically personal qualities, to identify ways and choose the tools to develop the advantages and get rid of disadvantages.

\subsection{Requirements for Professional Competencies}

Among the requirements for study of the basic disciplines of mathematical and natural Sciences, the following professional competences are allocated: to be able to acquire new knowledge, using modern educational and information technologies; to use the basic laws of natural Sciences in professional activities, to apply methods of mathematical analysis and modeling, theoretical and experimental research; to understand the nature and importance of information in the development of modern information society, to be aware of the dangers and threats that arise in this process, to comply with the basic requirements of information security, including the protection of state secrets; to master the basic methods, ways and means of obtaining, storing, processing information, to work with the computer as an information management tool; to make and present scientific and technical documentation; to plan and conduct the necessary experiments, to process information, including with the use of application software, to interpret the results and draw conclusions; to use physical-mathematical apparatus for analytical problems' solving arising in the course of professional activities; to select and apply appropriate methods for modeling of physical, chemical and technological processes.

\section{Results}

\subsection{Requirements for Interdisciplinary Relations}

In the process of physical and mathematical Sciences' studying technical College students are to learn to transfer the knowledge gained in the study of mathematics and physics for the processes explanation studied in other disciplines, to apply them when engineering problems' solving and the project tasks and practical engineering activities' implementation. The opposite aspect is important too- the ability to see in manufacture problem the physical-mathematical component, the ability to translate it into the language of mathematics to build mathematical model of the situation. Backbone role in the selection and structuring of the courses of mathematics and physics implementation are performed by integrative interdisciplinary connections, integration of teaching, research and practical activities of students, which are a mandatory element of students' training.

When selecting the content of teaching mathematics and physics it is necessary to realize the integrative potential of intra-disciplinary (between sections and disciplinary modules of the courses of mathematics and physics), interdisciplinary (math, physics and special disciplines) bonds; variable and invariant components of the curriculum of subjects "Mathematics" and "Physics"; between academic and professional activities of the future oil industry engineer (Zaripova et al., 2015b).

\subsection{Requirements for Professionally-Oriented Tasks}

The formation of the design and technical competence of future engineer-oilman involves not only the mastery of the necessary knowledge but also the ability to apply them in professional activity and in a constantly changing environment.

Modern educational concepts require the development of such directions to improve physical-mathematical training of the future engineer as the use of professionally-oriented tasks in the formation of professional 
competence of future engineer - oilman. Organization of teaching physics and mathematics through a system of professionally-designed, applying tasks and project tasks leads to the formation of the design and technical competence of students. Further, in the study of many sections of special disciplines there is a consolidation of physical-mathematical knowledge and the skills' development to use them when solving professionally oriented tasks. The use of the elements of a professional orientation in teaching mathematics can change not only the students ' understanding of the purpose of mathematics, but also change their simplistic ideas about the model of their future professional activity. Students begin to realize how engineering is knowledge-intensive. Awareness of the need for fundamental mathematical training to prepare them for successful professional activity "thus enhances motivation for learning mathematics and enhances the competence of the future engineer" (Zeer \& Symanyuk, 2005).

The coincidence of the phases of the engineer's professional activity with the stages of physics and math task's solving are presented in table 1 .

Table 1. The stages of the professional activities of the engineer and the applied physics and math task's solving

\begin{tabular}{cc}
\hline Stages of engineering activity & The stages of physics and math task's solving \\
(PMT) applied type
\end{tabular}

Getting of ready engineering task (ET) or the -

identification of the needs, some goals of the activity.

The formulation, clarification, specification of the Clarifying, understanding, specification of the engineering task applied math task.

Analysis, clarification, discussion of the ET terms, Updating of knowledge for PMT understanding updating of knowledge for ET understanding.

ET solution's search, schemes' development of ET, ideas' The search for PMT solutions, the ideas' formation formation for ET solution. for PMT solving.

The best approach to the solution

The best approach to the solution

Laboratory tests, pilot study of the objectives, the The creation of mathematical models of applied task creation of the object's model.

Solutions' implementation, creation of drawings, Task's solving diagrams.

The penetration of the project into manufacture.

Creative analysis of the solution's results, the search for other, more rational ways of solving.

For effectively and efficiently solving of the above mentioned tasks in the presentation of the studied section of mathematics and/or physics, at least, it is necessary to show the possibilities of its content's use in special subjects, techniques etc., and as a maximum, to consider the solution of complex applied tasks that require the ability to build mathematical models, to carry out the procedure of the measurements, assuming the existence of knowledge in the computational experiment. As the goals or main objectives of this direction in teaching mathematics and physics the formation of skills of students to highlight the mathematical and physical basis of technical objects and technological processes, to correlate it with the scientific and technical elements of the object, as well as the formation of certain intellectual skills which are necessary in the manufacture activity can be considered. Students should learn to transfer the knowledge gained in teaching physics and mathematics, to explain the processes and phenomena studied in other disciplines, to apply them when solving engineering tasks and the implementation of project tasks which are close to practical engineering activities. However, with all this, it's important to see engineering task its physical-mathematical component, translate it into the language of mathematics to build mathematical model of the situation. This relationship with future professional activity through meaningful formulation of physical and mathematical tasks, mathematical modeling and implementation of project activities in the process of learning physics and mathematics contributes to the genuine interest of the students and their motivation. 


\section{Discussions}

When structuring the content of teaching physics and mathematics researchers propose to be guided by such principles as: uninterrupted continuity (taking into account the positive experience gained in domestic and foreign practice of teaching mathematics and physics, compliance of basic (invariant) and additional (variable) parts of mathematics and physics), variability (in order to ensure the implementation of the same content based on a variety of scientific and methodological approaches), differentiation (to ensure compliance with individual abilities and level of physical-mathematical training of the trainee) (Balykbaev \& Primbetova, 2010), scientific, systematic, regularity and consistency, visibility and accessibility (Dorofeev, 2005; Lerner, 2005; Oganesyan, Kolyagin, Lukankin \& Sanninsky, 1980) Problem of content and process selection and learning of physics and mathematics, aimed at the development of methods of intellectual and practical activities that are required in professional activities interested M. A. Choshanov (1996). The author notes that along with the challenges of interdisciplinary content, bearing the fundamental theoretical nature, to achieve the purpose of formation of professional competence of the future specialist, widely the tasks in the solution of which are included the knowledge, abilities and skills that will be demanded in the future professional activity of students should be used.

The content's selection of learning subjects "Mathematics" and "Physics", aimed at the development of design and technical competence of students in the technical University of oil and gas profile includes an extension of the interdisciplinary component of the curricula in mathematics and physics, the inclusion in the content of training courses of training material from other areas of knowledge and practice. Undoubtedly, the current level of pedagogical science's development and the reforms taking place in higher education, require consideration of interdisciplinary connections (IDC) as a means of formation of future specialists' professional competence. But the implementation of interdisciplinary approach in Russian universities is disturbed by weak development of the theoretical aspect of interdisciplinary connections' specify in higher professional education, insufficiency of teachers' training at teachers' training universities in the aspect of pedagogical theory and methods of teaching, the traditional separation of various departments' work and faculty within a single Department (Mashkova \& Sidnev, 2007). In studies in which the integration of the education's content is considered as an object of study, it is customary to distinguish two main approaches: content (aim - to create in students a system of generalized knowledge) and procedural (goal - creation of a general system for different objects of activity).

Intra subject and inter subject integration mechanisms in education are aimed at the formation of the system integrity of professional competence, integrative worldview, system ideas about the interaction of different Sciences common to several objects of cognitive abilities. During the birth of interdisciplinary connections' theory (1950-1960-ies), teachers considered three kinds of interdisciplinary connections: follow up connections (teacher organizes the theme learning updating the training material, which was passed), related (appeal to the topics being studied in other subjects), and advanced (teacher prepares students to accept new material) (Korotkov, 2006). Currently, teachers allocate about fifty kinds of interdisciplinary connections, which can be attributed to meaningful information; operationally-activity; organizational-methodical. "The problem of realization of inter subject communications in the graduate school exists on two levels. Macro level is preparation of standard working curricula and plans of separate disciplines, the development of state standards and creation of manuals, which implements an integrative approach. The micro level is the level of various educational technologies' use in the teaching of separate disciplines" (Mashkova \& Sidnev, 2007). The implementation of the principle of interdisciplinary connections in the higher technical school comes to drawing up a model of working curricula and plans of separate disciplines, creating manuals that implement integrative, interdisciplinary approach. Challenges of interdisciplinary content allow to consolidate the basic, special concepts give an idea of the future professional activity as a single system consisting of physical, chemical, hydrodynamic, economic, and other processes occurring either sequentially or in parallel. Connection between objects is one of the basic requirements of didactics of vocational education. There is an indirect result of interdisciplinary connections' use in teaching understanding their essence by students. Interdisciplinary approach's possession is one of the main professional competences of oil industry engineer. Most modern methods of geophysical modeling and oil and gas fields' development involve the use of various research methods (lithological, geochemical, hydrodynamic, etc.), i.e. are of interdisciplinary character. However, the development of interdisciplinary connections requires a thorough teacher training, because in the absence of special training and experience of systematic teaching the teacher cannot possess professional content and methodology of other disciplines (Mashkova \& Sidnev, 2007).

\section{Conclusion}

Thus, the modern requirements to the content of the subjects "Mathematics" and "Physics", aiming at the formation of the design and technical competence of future experts of a technical profile, are determined by the list 
of occupational challenges facing a modern engineer, the transition of industries to knowledge-intensive technologies and the need for active participation of future technical specialists in their development and implementation, requiring from the graduates their formed common cultural and professional competences.

The content of teaching mathematics and physics aimed at the formation of the design and technical competence of future technical specialists, should consider the following requirements:

- it is necessary to preserve the integrity and thoroughness of the disciplines, forming a scientific and logical thinking of the student;

- the content of teaching mathematics and physics, in addition to fundamental backbone of scientific knowledge, should reflect the main objects of professional activity of a future specialist technical profile, to account for his or her actions' system as an oil industry engineer;

- the content of teaching mathematics and physics of the future of petroleum engineers should be aimed at the formation of their logical and technical thinking needed in their future professional activity, requiring the formation of the design and predictive skills and competencies.

- it is necessary the organized and consistent reflection of interdisciplinary connections of the content of teaching mathematics and physics, revealing the other applications of these disciplines and their relationship with the prospects of innovative manufacture;

- the content is to show the possibilities of mathematics and physics' application in the process of modeling and design in professionally-designed learning tasks' solving and educational projects' implementation.

The content of teaching physics and mathematics should be designed on the basis of general principles of continuity, succession, diversity, differentiation, scientific nature, consistency, regularity and consistency, clarity, and accessibility, as well as the principles of professional orientation, modularity, interdisciplinary integration, problems and innovation.

\section{References}

Balykbaev, T. S., \& Primbetova, G. S. (2010). The system of external evaluation of the quality of education. Education, 1, 17-24.

Choshanov, M. A. (1996). Flexible technology problem-modular education. Moscow.

Dorofeev, A. V. (2005). Professional competence as an indicator of the quality of education. Higher education in Russia, 4, 30-33.

Korotkov, E. M. (2006). Quality Management Education: Textbook for universities. Moscow: Academic Portrait Press.

Lerner, P. S. (2005). Engineer of the third millennium: Textbook for vocational and professional orientation and profile training of schoolboys. Moscow: Academy Press.

Masalimova, A. R., \& Nigmatov, Z. G. (2015). Structural-Functional Model for Corporate Training of Specialists in Carrying Out Mentoring. Review of European Studies, 7(4), 39-48. http://dx.doi.org/10.5539/res.v7n4p39

Mashkova, E. A., \& Sidnev, A. V. (2007). Interdisciplinary communication as a means of formation of professional competence of students of universities of petroleum. The success of modern science, 7, 45-49.

Oganesyan, V. A., Kolyagin, Y. M., Lukankin, G. L., \& Sanninsky, V. J. (1980). Methods of teaching mathematics in high school. General Procedure. Moscow.

Plakhova, V. G. (2009). Formation of mathematical competence of students of technical colleges. PhD Thesis. Saransk.

Shershneva, V. A. (2011). Formation of mathematical competence of students of engineering colleges on the basis multiparadigmatic character approach. Moscow.

Zaripova, I. M., Merlina, N. I., Valeyev, A. S., Upshinskaya, A. E., Zaripov, R. N., Khuziakhmetov, A. N., \& Kayumova, L. A. (2015). Methodological Support for Professional Development of Physical-Mathematical Sciences Teachers, Aimed At Forming the Project-Technical Competency of Technical University Students. Review of European Studies, 7(3), 313-318. http://dx.doi.org/10.5539/res.v7n3p313

Zaripova, I. M., Shaidullina, A. R., Upshinskaya, A. E., Sayfutdinova, G. B., \& Drovnikov, A. S. (2014). Modeling of Petroleum Engineers Design-technological competence forming in physical-mathematical disciplines studying process. American Journal of Applied Science, 11(7), 1049-1053. http://dx.doi.org/10.3844/ajassp.2014.1049.1053 
Zeer, E., \& Symanyuk, E. (2005). Competence approach to the modernization of vocational education. Higher education in Russia, 4, 23-29.

\section{Copyrights}

Copyright for this article is retained by the author(s), with first publication rights granted to the journal.

This is an open-access article distributed under the terms and conditions of the Creative Commons Attribution license (http://creativecommons.org/licenses/by/3.0/). 